\title{
Co-Precipitation Synthesis and Characterization of Nanocrystalline Zinc Oxide Particles Doped with $\mathrm{Cu}^{2+}$ Ions
}

\section{Mergoramadhayenty Mukhtar, Lusitra Munisa, Rosari Saleh ${ }^{*}$}

Departemen Fisika, FMIPA-Universitas Indonesia, Depok, Indonesia.

Email: *rosari.saleh@ui.ac.id

Received May $8^{\text {th }}, 2012$; revised June $10^{\text {th }}, 2012$; accepted July $9^{\text {th }}, 2012$

\begin{abstract}
Nanocrystalline $\mathrm{Cu}$-doped $\mathrm{ZnO}$ particles were synthesized by the co-precipitation method. The composition, structural, optical and magnetic characterizations were performed by energy dispersive X-Ray spectroscopy, X-Ray diffraction, UV-Visible spectrometer, and vibrating sample magnetometer. The results confirmed that nanocrystalline $\mathrm{Cu}$-doped $\mathrm{ZnO}$ particles have a hexagonal wurtzite structure with a high degree of crystallization and a crystallite size of $10-16$ $\mathrm{nm}$. For $\mathrm{Cu}$ above $11 \mathrm{at} \%$, the X-Ray diffraction pattern possessed $\mathrm{CuO}$ secondary phase which shows the solubility limit of $\mathrm{Cu}$ in the $\mathrm{ZnO}$ lattice. $\mathrm{Up}$ to $11 \%$ at $\mathrm{Cu}$, the presence of $\mathrm{Cu}$ in the $\mathrm{ZnO}$ lattice as $\mathrm{Zn}$ substitution indicated by an in- crease in lattice parameter values. Nanoparticles showed weak ferromagnetic characteristics at room temperature. The absence of secondary phase related to magnetic precipitate shown intrinsic ferromagnetic behaviour.
\end{abstract}

Keywords: $\mathrm{Cu}$-Doped ZnO; Structural Properties; Room Temperature Ferromagnetism

\section{Introduction}

Wide band-gap oxide semiconductors, when doped with transition metal ions (Mn, Fe, Co and $\mathrm{Ni}$ ) have attracted much attention for their promising versatile applications.

$\mathrm{ZnO}$ based ferromagnetic semiconductor are paid much attention since the theoretical prediction of room temperature ferromagnetism by Dietl et al. in 2000 [1]. They used mean field theory to estimate Currie temperature $\left(\mathrm{T}_{\mathrm{C}}\right)$ of ferromagnetic semiconductor and they predicted that room temperature ferromagnetism can be created by substituting $\mathrm{Mn}$ ion in wide band gap semiconductor such as $\mathrm{ZnO}$ or GaN. Due to its wide band gap and exciton binding energy of $60 \mathrm{meV}$, transition metal doped $\mathrm{ZnO}$ is attractive for many UV photonic and transparent electronic applications [2]. Numerous experimental studies have proved the existence of room temperature ferromagnetism in $\mathrm{Mn}$-, $\mathrm{Fe}-, \mathrm{Co}-$ and Ni-doped $\mathrm{ZnO}$ [3-6]. Room temperature ferromagnetism has indeed been reported in many of transition metal-doped $\mathrm{ZnO}$. However, the origin of ferromagnetism in transition metaldoped oxide semiconductors remain controversial, some report claims that the room temperature ferromagnetism in TM-doped oxides might come from precipitation of magnetic cluster or secondary magnetic phases $[7,8]$,

${ }^{*}$ Corresponding author. while others claims that ferromagnetic ordering is intrinsic [9]. Motivated by these contradictory results, experimental studies have addressed the magnetic properties of $\mathrm{Cu}$-doped, since it is known that the metallic $\mathrm{Cu}$ as well as all possible $\mathrm{Cu}$-based oxide such as $\mathrm{Cu}_{2} \mathrm{O}$ or $\mathrm{CuO}$ is nonmagnetic [10]. Therefore, several scientists suggested that if any ferromagnetism is observed in $\mathrm{Cu}$-based system, then it will undoubtedly be the intrinsic property of the material [11]. However, the experimental results still remain controversial; Buchholz et al. [12] nonferromagnetism in $n$-type $\mathrm{Cu}$-doped $\mathrm{ZnO}$ sample. On the contrary, other report claimed that, $n$-type $\mathrm{Cu}$-doped $\mathrm{ZnO}$ has ferromagnetic behavior [13]. The same results were also found in theoretical studies. Early theoretical investigation showed that ferromagnetic ordering cannot develop in $\mathrm{ZnO}$ doped with 25 at\% [14]. Later subsequent studies suggested that $\mathrm{ZnO}$ doped with low level of $\mathrm{Cu}$ concentration should be more succesful in producing ferromagnetism [15-17]. Furthermore, it is shown that the magnetism is very sensitive to the preparation methods and hence preparation conditions, even magnetic properties of $\mathrm{Cu}$-doped $\mathrm{ZnO}$ prepared by the same method for the same doping concentration show the lack of reproducibility.

In this paper, we present our investigation to understand the structural and magnetic properties of $\mathrm{Cu}$ doped 
nanocrystalline $\mathrm{ZnO}$ particles prepared through a coprecipitation method. The structural and magnetic properties were correlated to understand the origin of room temperature ferromagnetism in our samples.

\section{Experimental}

Nanocrystalline $\mathrm{Cu}$-doped $\mathrm{ZnO}$ particles in this work were synthesized by co-precipitation process. This method provides advantages, such as low synthesis temperature, small particle and simplicity of processing. The starting materials used in this experiment were copper sulfate monohydrate $\left(\mathrm{CuSO}_{4} \cdot 5 \mathrm{H}_{2} \mathrm{O}\right)$, Zinc sulfate hepta hydrate $\left(\mathrm{ZnSO}_{4} \cdot 7 \mathrm{H}_{2} \mathrm{O}\right), 25 \%$ aqueous Sodium hydroxide $(\mathrm{NaOH})$ which are all procured from Aldrich and Merck. All of the chemicals used are GR grade without further purification. To synthesize nanocrystalline $\mathrm{Cu}$-doped $\mathrm{ZnO}$ particles, two solutions, one containing the requisite amounts of $\mathrm{ZnSO}_{4} \cdot 7 \mathrm{H}_{2} \mathrm{O}$ and $\mathrm{CuSO}_{4} \cdot 5 \mathrm{H}_{2} \mathrm{O}$ in distilled water, and the other containing $44 \mathrm{mmol} \mathrm{NaOH}$ was prepared in $440 \mathrm{ml}$ of de-ionized water. The solution containing $\mathrm{ZnSO}_{4} \cdot 7 \mathrm{H}_{2} \mathrm{O}$ and $\mathrm{CuSO}_{4} \cdot 5 \mathrm{H}_{2} \mathrm{O}$ was then put into an ordinary ultrasonic cleaner using a $57 \mathrm{kHz}$ operating frequency for $2 \mathrm{~h}$ at $50^{\circ} \mathrm{C}$. Then, this solution was subsequently stirred with a magnetic stirrer at $80^{\circ} \mathrm{C}$. The $\mathrm{NaOH}$ solution was added until the final $\mathrm{pH}$ of the mixed solution reached to 12 . The mixed solution was further stirred for $0.5 \mathrm{~h}$ with constant stirring. So obtained solution was aged at room temperature for $18 \mathrm{~h}$. This solution was centrifuged and the precipitate that formed was seperated from the solution, and washed several times with ethanol and distilled water in order to remove residual and unwanted impurities. The obtained product was dried in a vacuum oven at $200^{\circ} \mathrm{C}$ for $1 \mathrm{~h}$ yielding brown $\mathrm{Cu}$ doped $\mathrm{ZnO}$ powder.

The composition of the samples was determined by energy dispersive X-Ray spectroscopy (EDX) using scanning microscope. The crystal structure and phase impurity were analysed using X-Ray diffraction (XRD) measurements at room temperature with a standard X-Ray diffractometer Philips PW 1710 and monochromatic $\mathrm{Cu}-$ $\mathrm{K} \alpha(\lambda=1.54060 \AA)$ radiation operated at $40 \mathrm{kV}$ and 20 $\mathrm{mA}$ in the range from $10^{\circ}$ to $80^{\circ}$. The calibration of the diffractometer was done using Si powder. Structural properties were further studied using Fourier transform infra red (FTIR) measurements. FTIR spectra of the powder samples were recorded using Shimadzu Fourier transform spectrometer. All spectra recorded on pressed pellet of the prepared samples in potassium bromide $(\mathrm{KBr})$ in the range of $400-4000 \mathrm{~cm}^{-1}$ with resolution of $4 \mathrm{~cm}^{-1}$.

In order to study the electronic interaction near the optical band gap due to addition of dopant atoms UV-Vis diffuse reflectance measurements were deployed. In the present work, measurements have been performed using a Shimadzu UV-Vis spectrophotometer with an integrating sphere attachment and spectralon reflectance standard in the wavelength range of $250-800 \mathrm{~nm}$. The diffuse reflectance, $R$, of the sample is related to the $\mathrm{Ku}$ belka-Munk function $F(R)$ by the relation:

$$
F(R)=(1-R)^{2} / 2 R
$$

The band gap energy of the samples were calculated from the diffuse reflectance spectra by plotting the $F(R)^{2}$ vs. energy and extrapolated it to $F(R)^{2}=0$.

Magnetic properties were experimentally studied by measuring magnetization as a function of external magnetic field at room temperature using Oxford Type 1.2 T vibrating sample magnetometer (VSM). These measurements were taken from 0 to \pm 1 Tesla field.

\section{Results and Discussion}

Figure 1 shows a typical energy dispersive X-Ray (EDX) spectrum of $\mathrm{Cu}$-doped $\mathrm{ZnO}$ nanoparticles. In addition to an oxygen peak at $0.53 \mathrm{keV}$ and a $\mathrm{Zn}$ signal at $1.01,8.69$ and $9.53 \mathrm{keV}$, a $\mathrm{Cu}$ peak at $8.69 \mathrm{keV}$ was observed. Quantitative results of the $\mathrm{Cu} / \mathrm{Zn}$ ratio are calculated from the area of the corresponding spectra $\mathrm{K}$ lines. The amount of $\mathrm{Cu}$ in the nanoparticles has been found to vary between 6 and 23 at\%. The inset of Figure 1 illustrates the $\mathrm{Cu}$ incorporation in nanoparticles as a function of the initial cations ratio in the starting solution.

Figure 2 shows the results of XRD patterns of nanocrystalline $\mathrm{Cu}$-doped $\mathrm{ZnO}$, undoped $\mathrm{ZnO}$ and $\mathrm{CuO}$ particle samples.

The diffraction peak for sample doped with 6 and 11 at $\%$ of $\mathrm{Cu}$ can be indexed to the hexagonal wurtzite

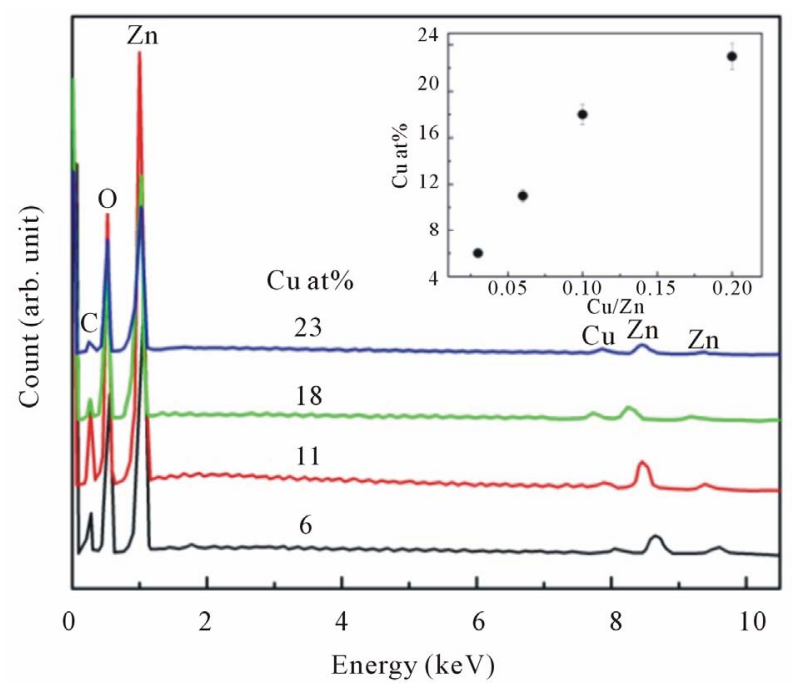

Figure 1. EDX spectra of Cu-doped nanocrystalline $\mathrm{ZnO}$ particles for various doping concentrations. For clarity, the spectra are shifted vertically. The inset shows the $\mathrm{Cu}$ incorporation in the nanoparticles as a function of the initial cation ratio in the starting solution. 


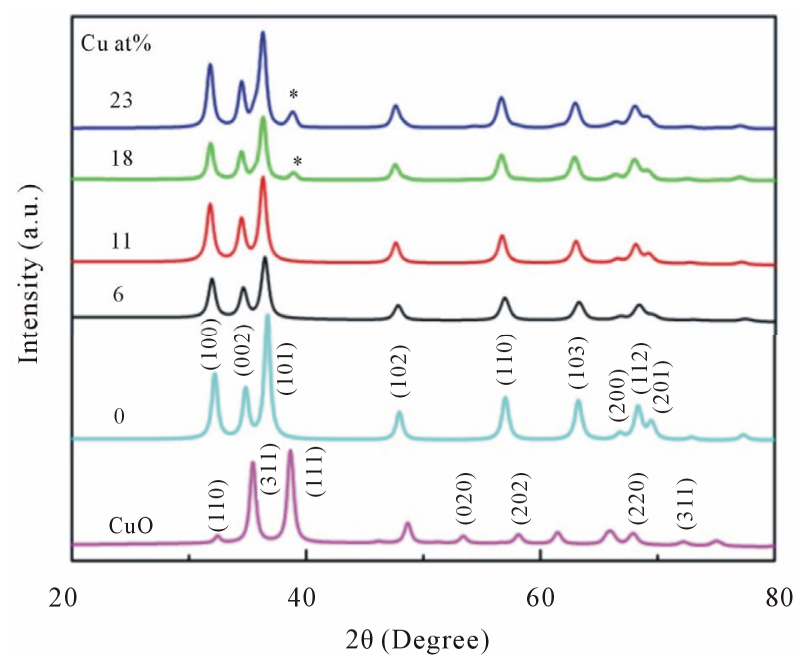

Figure 2. XRD patterns of undoped, $\mathrm{CuO}$ and $\mathrm{Cu}$-doped nanocrystalline $\mathrm{ZnO}$ particles synthesized with different concentrations of $\mathrm{Cu}$.

structure of $\mathrm{ZnO}$ with nine prominent peaks, clearly suggested that the samples are in single phase within detection limit. No detectable diffraction peak for any secondary or impurity phase such as $\mathrm{CuO}$ was found in both samples. Moreover, we can see the Bragg peaks of our $\mathrm{Cu}$-doped $\mathrm{ZnO}$ slightly move to lower angle side compared to that of the undoped $\mathrm{ZnO}$ sample as shown in Figure 3, indicated an important evidence of replacement of $\mathrm{Zn}^{2+}$ with $\mathrm{Cu}^{2+}$ ions [18].

However, for samples doped with $\mathrm{Cu}$ concentration of 18 and 23 at $\%$, reflection (111) of $\mathrm{CuO}$ crystalline structure marked by $(*)$ in its corresponding XRD pattern arises. This means a small part of $\mathrm{CuO}$ may have been incorporated into the $\mathrm{ZnO}$ wurtzite lattice or decompose. This result indicated that the doping limit for our $\mathrm{Cu}$-doped $\mathrm{ZnO}$ sample is below $18 \mathrm{at} \%$ of $\mathrm{Cu}$. However, there is no noticeable shift in the XRD peak positions towards lower angles for samples doped with 18 and 23 at $\%$ compared to samples doped with lower doping concentrations. We have analyzed the effect of doping on the structural changes, such as the lattice parameter, the unit cell volume and average crystallite size. The lattice parameters are estimated from the XRD peaks positions and refined using Rietveld analysis technique. The lattice parameters of undoped $\mathrm{ZnO}$ particles were $a=0.3218$ $\mathrm{nm}$ and $c=0.5155 \mathrm{~nm}$, which is similar with a standard values [19]. For $\mathrm{Cu}$-doped $\mathrm{ZnO}$ samples, the lattice parameters are slightly higher than undoped $\mathrm{ZnO}$.

Lattice parameters ( $a$ and $c$ ), unit cell volume $(V)$, and average crystallite size $(<\mathrm{D}>)$ calculated for different doping concentrations are plotted in Figure 4. The lattice parameters $a, c$ and $V$ increased with increasing doping concentrations. The unit cell volume continuously increases, which can be explained by looking at the ionic

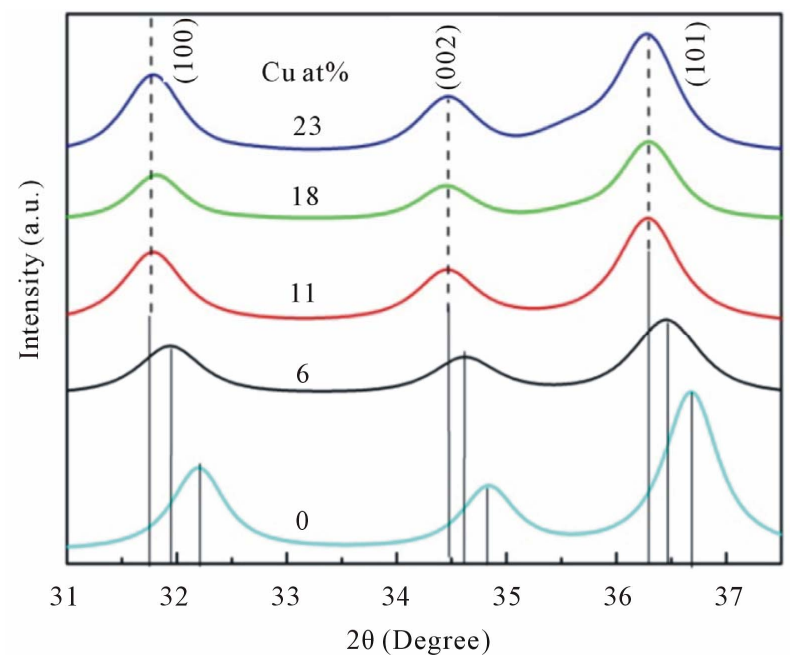

Figure 3. Doping-induced peak shift. This is attributed to $\mathrm{Cu}^{2+}$ is replaced in the $\mathrm{Zn}^{2+}$ atomic site.

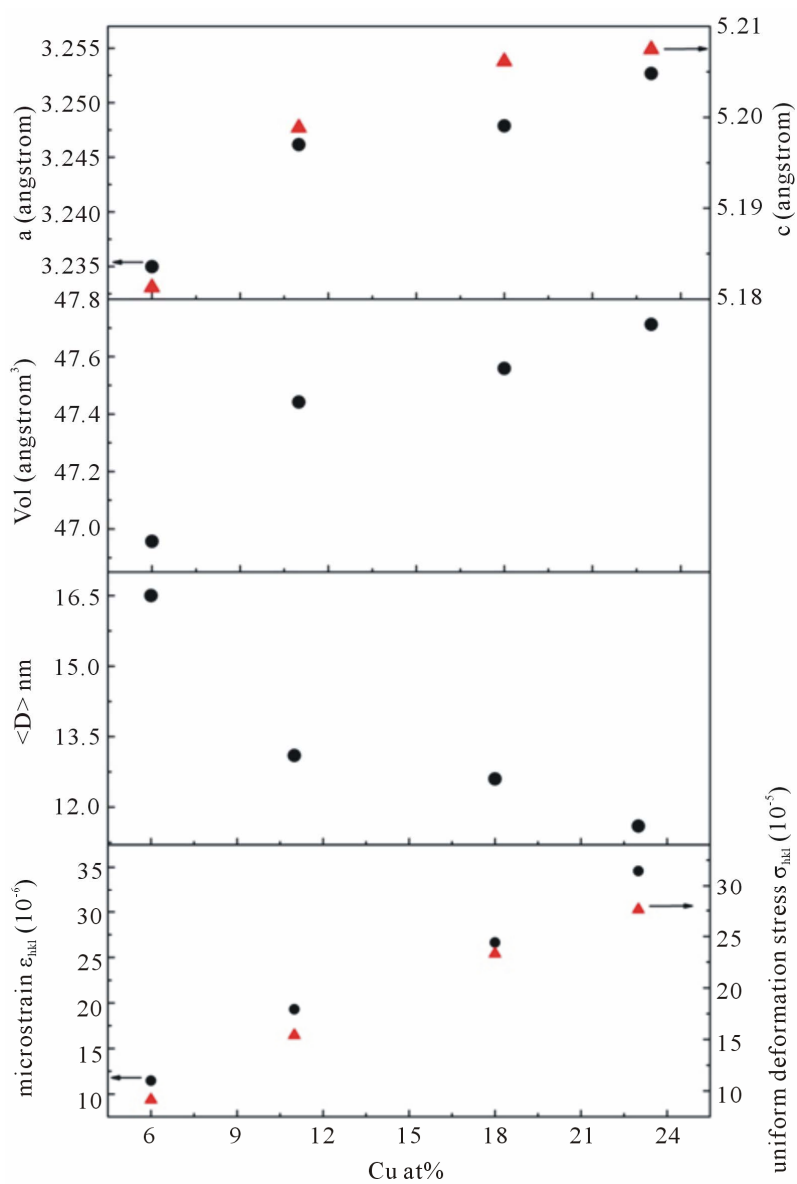

Figure 4. The lattice parameters $a, c$, cell volume $V$, average crystallite size and micro strain of $\mathrm{Cu}$-doped nanocrystalline $\mathrm{ZnO}$ particles as a function of doping concentration.

radii.

The substitution of the smaller $\mathrm{Zn}^{2+}$ ion by the $\mathrm{Cu}^{2+}$ ion is expected to result in an expansion of the unit cell 
volume. In addition, XRD pattern can be utilized to evaluate lattice strain and stress due to defect or vacancies using Williamson-Hall relation [20]:

$$
\Delta_{h k l} \cos \Theta=\kappa \lambda /<\mathrm{D}>+4 \varepsilon \sin \Theta
$$

where $k$ is shape factor (0.89), $\lambda$ is X-Ray wavelength, $\Delta_{h k l}$ is line broadening at half-height, $\Theta$ is Bragg angle of the particles and $\varepsilon$ is the microstrain.

According to Hooke's law, the stress is proportional to the strain with the constant of proportionality being the modulus of elasticity or Young modulus denoted by $\Delta_{h k l}$. Therefore, as a result, the Equation (1) may be modified as:

$$
\Delta_{h k l} \cos \Theta=\kappa \lambda /<\mathrm{D}>+4 \sin \Theta \sigma / E_{h k l}
$$

where $\sigma$ is the uniform stress. The Equation (2) represents a straight line between $4 \sin \Theta \sigma / E_{h k l}$ as an $\mathrm{x}$-axis and $\Delta_{h k l} \cos \Theta$ as an y-axis. The slope of the line gives the uniform stress $\sigma$ and intercept of this line gives crystallite size $\langle\mathrm{D}\rangle$. It is observed that the strain in Cu-doped samples varies with doping concentrations. The strain is higher as the dopant is increased. It is seen that more $\mathrm{Cu}$ content is introduced into the sample, the stronger tensile is, or more created compression stress is. It is known that

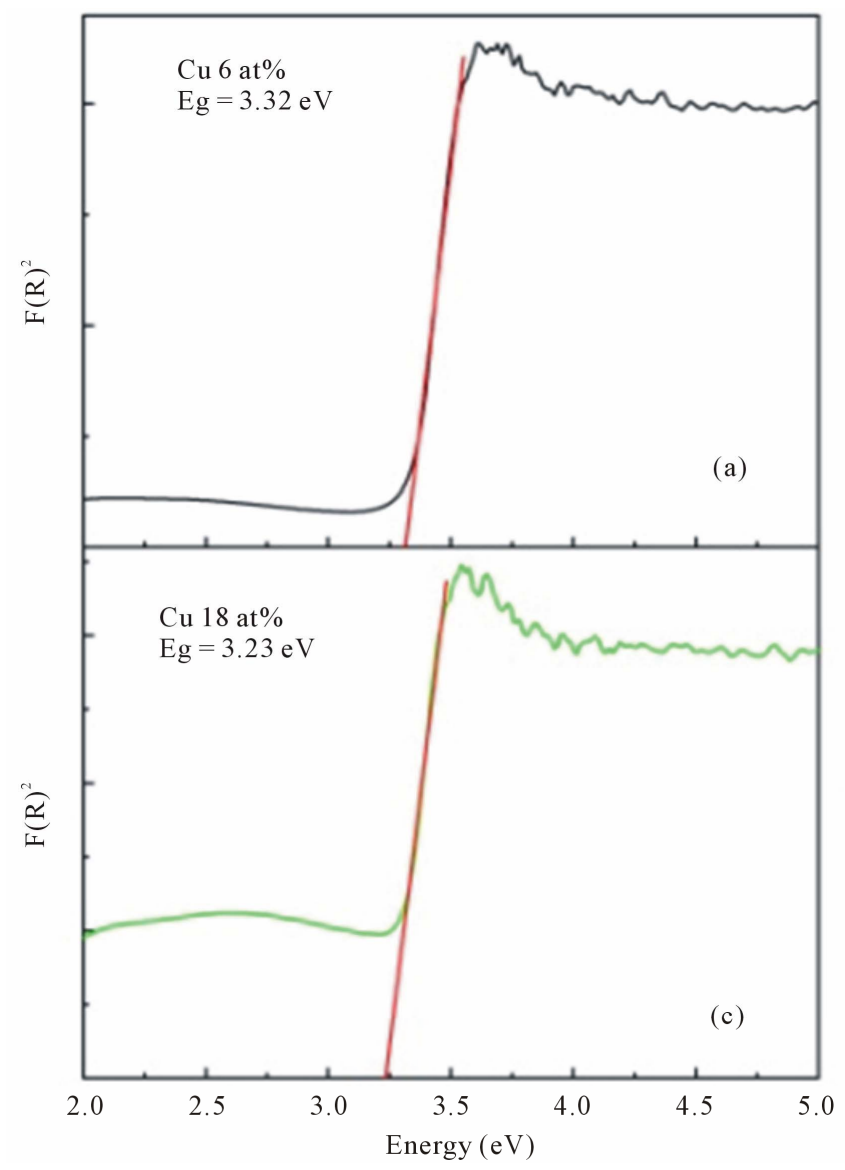

the more oxygen vacancies are introduced in the $\mathrm{ZnO}$ matrix, the stronger the resulting stress [21]. Accordingly, we believed that our $\mathrm{Cu}$-doped $\mathrm{ZnO}$ samples contain oxygen vacancies.

The crystallite size $<\mathrm{D}>$ calculated from Williamson and Hall plot was found to decrease with increasing $\mathrm{Cu}$ dopant. The average crystallite size was found to be 18 $\mathrm{nm}$ for undoped $\mathrm{ZnO}$ and 13.45 for the $\mathrm{Cu}$-doped samples, which indicates that the samples are nanocrystalline.

Optical characterization was carried out by measuring the diffuse reflectance at room temperature. All spectra were taken in the range of $200-800 \mathrm{~nm}$. The optical gap was estimated from diffuse reflectance spectra by plotting the square of the Kubelka-Munk function $F(R)^{2}$ given by the relation $F(R)=(1-R)^{2} / 2 R$, where $R$ is the magnitude of reflectance as a function of energy. Figure 5 shows the $F(R)^{2}$ as a function of energy for all $\mathrm{Cu}$ doped $\mathrm{ZnO}$ samples and to obtained the optical gap the linear part of $F(R)^{2}$ curve was extrapolated until it intersects the energy axis at $F(R)^{2}=0$. The optical band gap of the various compositions in $\mathrm{Cu}$-doped $\mathrm{ZnO}$ samples is shown in Table 1. For undoped $\mathrm{ZnO}$ the band gap comes out to be $3.4 \mathrm{eV}$ and is in accordance with the

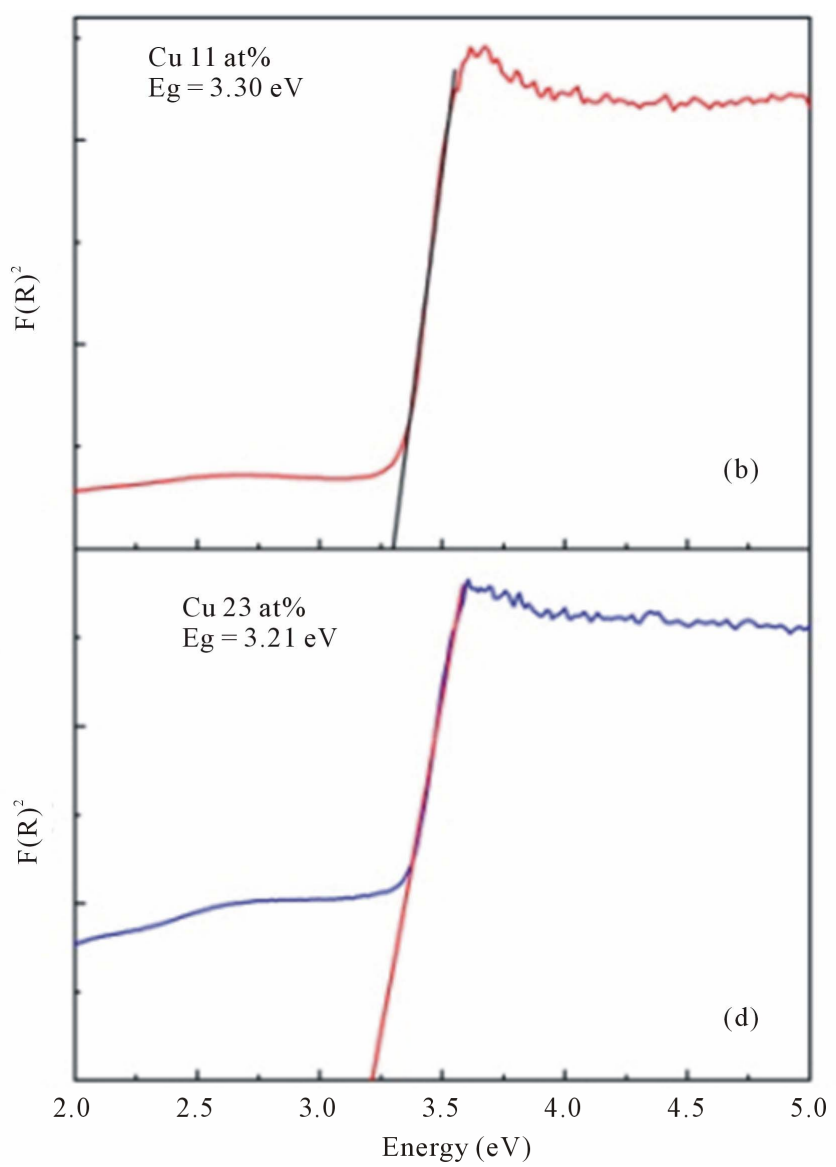

Figure 5. The $F(R)^{2}$ as a function of energy for all $\mathrm{Cu}$-doped nanocrystalline $\mathrm{ZnO}$ particles synthesized with various doping concentrations. 
Table 1. Rietveld refined XRD data and optical gap of $\mathrm{Cu}$-doped nanocrystalline $\mathrm{ZnO}$ particles.

\begin{tabular}{ccccccccc}
\hline Sample & at $\%$ & $\mathrm{a}(\AA)$ & $\mathrm{c}(\AA)$ & $\mathrm{V}\left(\AA^{3}\right)$ & $<\mathrm{D}>\mathrm{nm}$ & $\varepsilon\left(10^{-4}\right)$ & $\mathrm{Eg}(\mathrm{eV})$ \\
\hline \multirow{2}{*}{$\mathrm{Cu}$ doped $\mathrm{ZnO}$} & 0 & 3.2180 & 5.1550 & 47.7017 & 18.0 & 10.7 & 3.46 \\
& 6 & 3.2350 & 5.1810 & 46.9570 & 16.5 & 11.5 & 3.32 \\
& 11 & 3.2460 & 5.1990 & 47.4420 & 13.1 & 19.3 & 3.30 \\
& 18 & 3.2480 & 5.2060 & 47.5590 & 12.6 & 26.6 & 3.23 \\
\hline
\end{tabular}

reported value [22-24]. For $\mathrm{Cu}$-doped $\mathrm{ZnO}$ the optical gap was obtained as 3.32, 3.30, 3.23 and $3.21 \mathrm{eV}$, for doping concentration $6,11,18$ and 23 at $\%$, respectively.

The band gap is found to decrease with increase $\mathrm{Cu}$ concentration in $\mathrm{ZnO}$. Similar mitigation of the band gap with increasing $\mathrm{Cu}$ concentration has been reported earlier $[25,26]$. The inherent reason for red shift in band edge in transition metal doped $\mathrm{ZnO}$ samples is due to the change of the sp-d exchange interaction between the band electrons and the localized d-electron of the $\mathrm{Cu}^{2+}$ ions [27].

Infrared absorbance spectra are employed to study the vibration bands due to $\mathrm{Zn}-\mathrm{O}$ bond, the changes due to $\mathrm{Cu}$ substitution and hydrogen bonding. Typical infrared absorption spectra of samples synthesized at different doping concentrations are displayed in Figure 6. For all $\mathrm{Cu}$-doped samples the strong absorption peaks in the range of $400-700 \mathrm{~cm}^{-1}$ could be attributed to $\mathrm{ZnO}$ stretching modes $[28,29]$. These stretching modes are indicative of successful synthesized of nanocrystalline $\mathrm{ZnO}$ particles as already confirmed by XRD and EDX studies. At the same time we can also observed an absorption peak around 1646, 1390 and $1121 \mathrm{~cm}^{-1}$ corresponds to $\mathrm{OH}$ bending mode, $\mathrm{C}-\mathrm{OH}$ plane bending and $\mathrm{C}-\mathrm{OH}$ out-of-plane bending, respectively [30].

A broad band in the region $2900-3700 \mathrm{~cm}^{-1}$ can be explained as overlaping of physically absorbed water, $\mathrm{O}-\mathrm{H}$ stretching modes and $\mathrm{C}-\mathrm{H}$ stretching modes. $\mathrm{C}-\mathrm{H}$ local vibrational modes between 2800 and $3100 \mathrm{~cm}^{-1}$ have been observed in a number of semiconductor such as amorphous silicon carbon (a-SiC:H), GaAs, and $\mathrm{GaN}$ [31-33]. In these materials the local vibrational modes are assigned to symmetric and antisymmetric $\mathrm{C}-\mathrm{H}$ stretching modes. To obtain information more clearly on the local vibrational modes correspond to $\mathrm{OH}$ modes we focalized our analysis on the infrared absorption range of interest, namely in a wave number range of $2900-3700$ $\mathrm{cm}^{-1}$.

All spectra can be deconvoluted into two peaks around $2990 \mathrm{~cm}^{-1}$ attributed to $\mathrm{CH}$ stretching mode and 3400 $\mathrm{cm}^{-1}$ associated with physically absorbed water and $\mathrm{O}-\mathrm{H}$ stretching modes (dashed line in Figure 7). The integrated absorption is evaluated using the sum of the ab- sorption areas from the fits data. As the dopant concentration is increased, the integrated absorption of the $\mathrm{OH}$ and $\mathrm{CH}$ stretching modes appears to be independent of

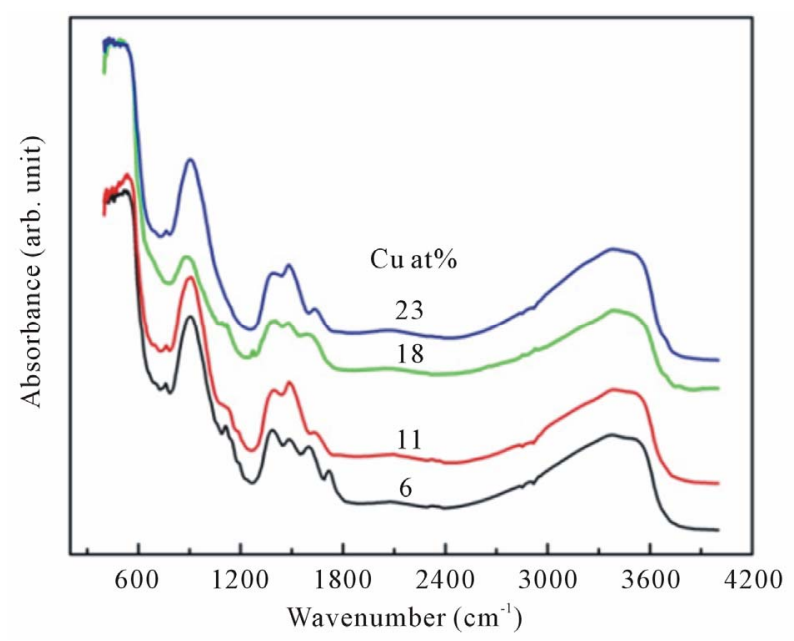

Figure 6. The infrared spectra of $\mathrm{Cu}$-doped nanocrystalline ZnO particles synthesized with various doping concentrations.

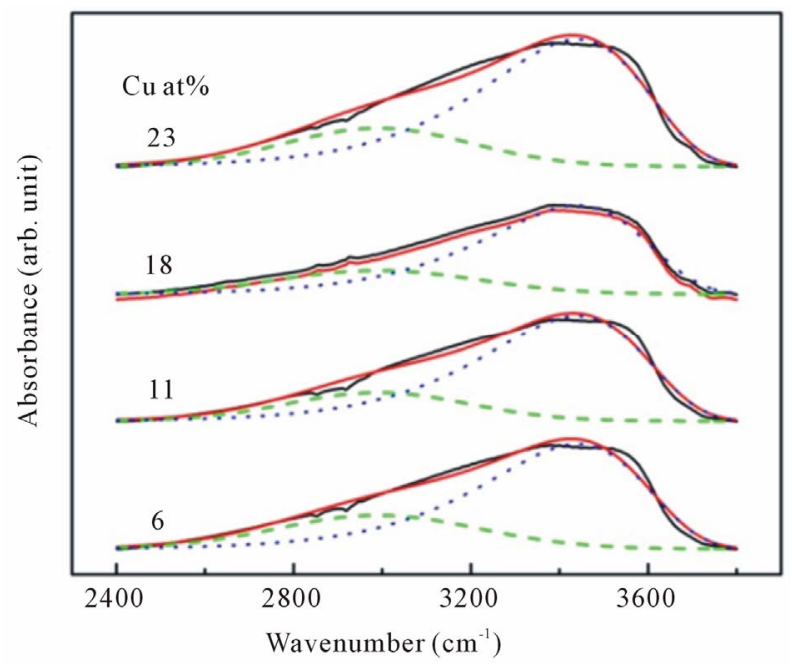

Figure 7. Representative deconvolution of $\mathrm{C}-\mathrm{H}$ stretching (dash line) and $\mathrm{O}-\mathrm{H}$ stretching (dotted line) modes of infrared absorption band in the range of $2400-3900 \mathrm{~cm}^{-1}$ for Cu-doped ZnO nanoparticles. 


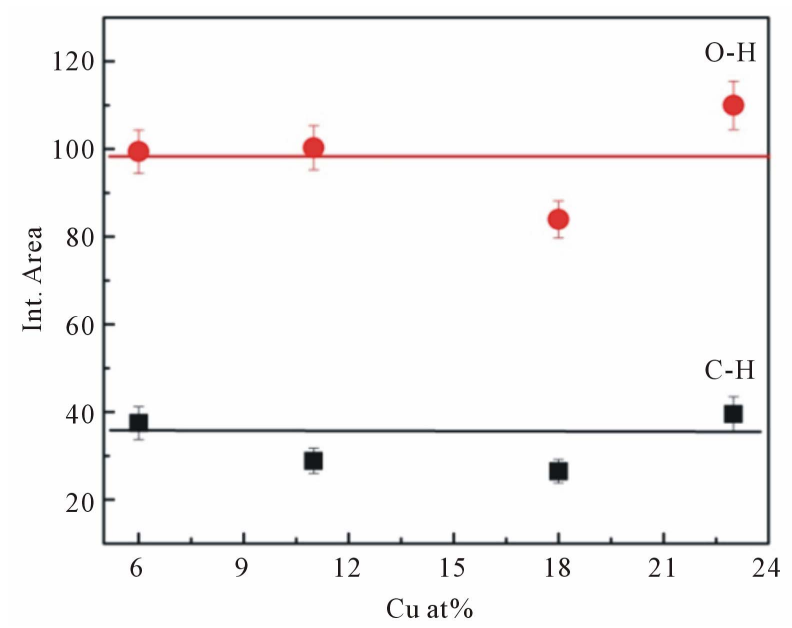

Figure 8. Integrated absorption of $\mathrm{C}-\mathrm{H}$ stretching mode at $2990 \mathrm{~cm}^{-1}$ and $\mathrm{O}-\mathrm{H}$ stretching mode at $3400 \mathrm{~cm}^{-1}$.

the dopant concentrations in the samples (Figure 8).

The magnetization as a function of magnetic field (M-H loop) measured at room temperature for samples doped with $6,11,18$ and 23 at $\%$ of $\mathrm{Cu}$ are studied using

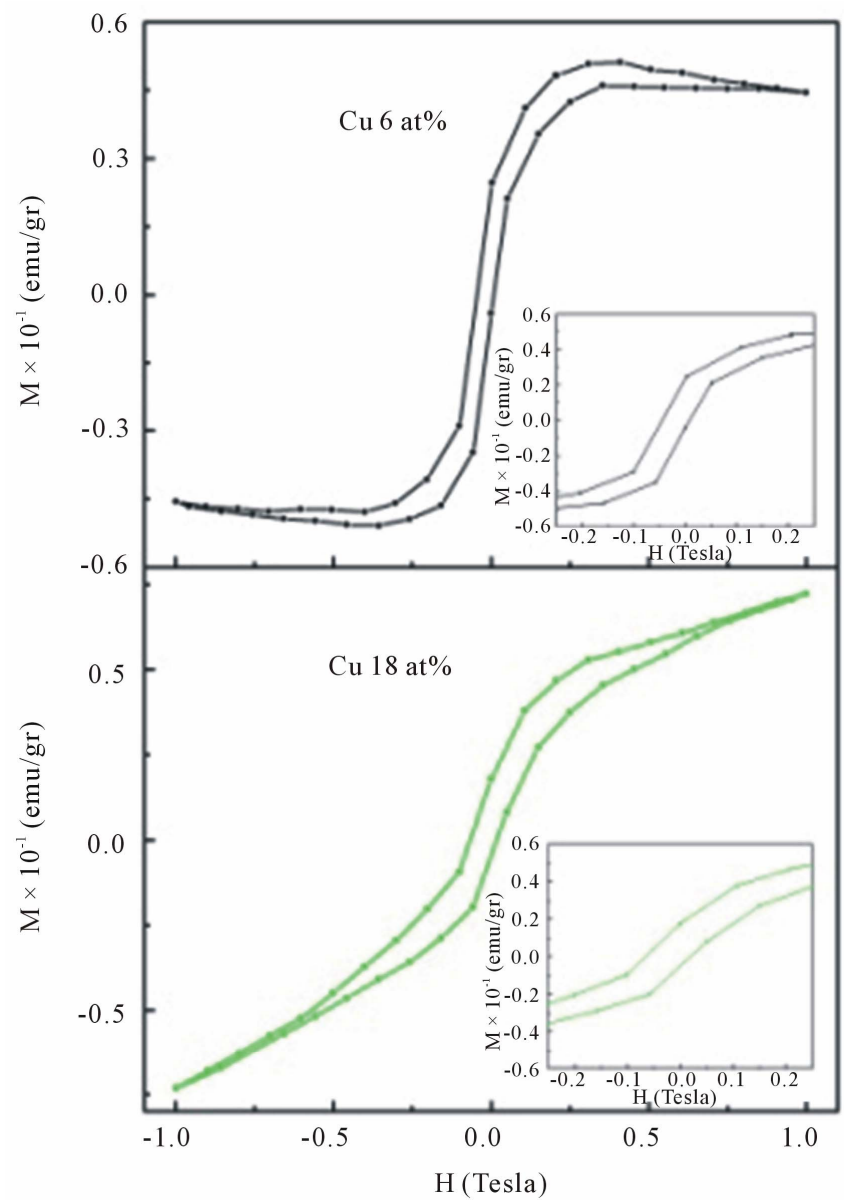

VSM in the applied magnetic field range of $0-1 \mathrm{~T}$. The maximum value of magnetic moment per $\mathrm{Cu}$ atom increased with increasing dopant atoms.

The corresponding curves are shown in Figure 9 reveal the dependence of magnetization on the applied magnetic field for all doped samples. The inset of Figure 9 clearly displays the magnetization data with an open loop for all $\mathrm{Cu}$-doped samples. The variation in saturation magnetization, remnant magnetization and coercivity for different $\mathrm{Cu}$-doped samples is presented in Table 2. However, the magnetization values are much smaller than the $1 \mu_{\mathrm{B}} / \mathrm{Cu}$ expected for $\mathrm{Cu}^{2+}$ ions homogenously dispersed in the $\mathrm{ZnO}$ bulk.

Since $\mathrm{Cu}$ and related oxides are nonmagnetic materials at room temperature, the observed ferromagnetism is thought to be intrinsic properties of the $\mathrm{Cu}$-doped $\mathrm{ZnO}$ [34]. A similar result was also found by Sharma et al. [35]. Sudakar et al. [36] reported that $\mathrm{Cu}$-doped $\mathrm{ZnO}$ films with concentration lower than 1 at $\%$ exhibited ferromagnetic behavior with large saturation magnetization, however, for higher doping concentrations, the saturation magnetization decreased drastically. They proposed that

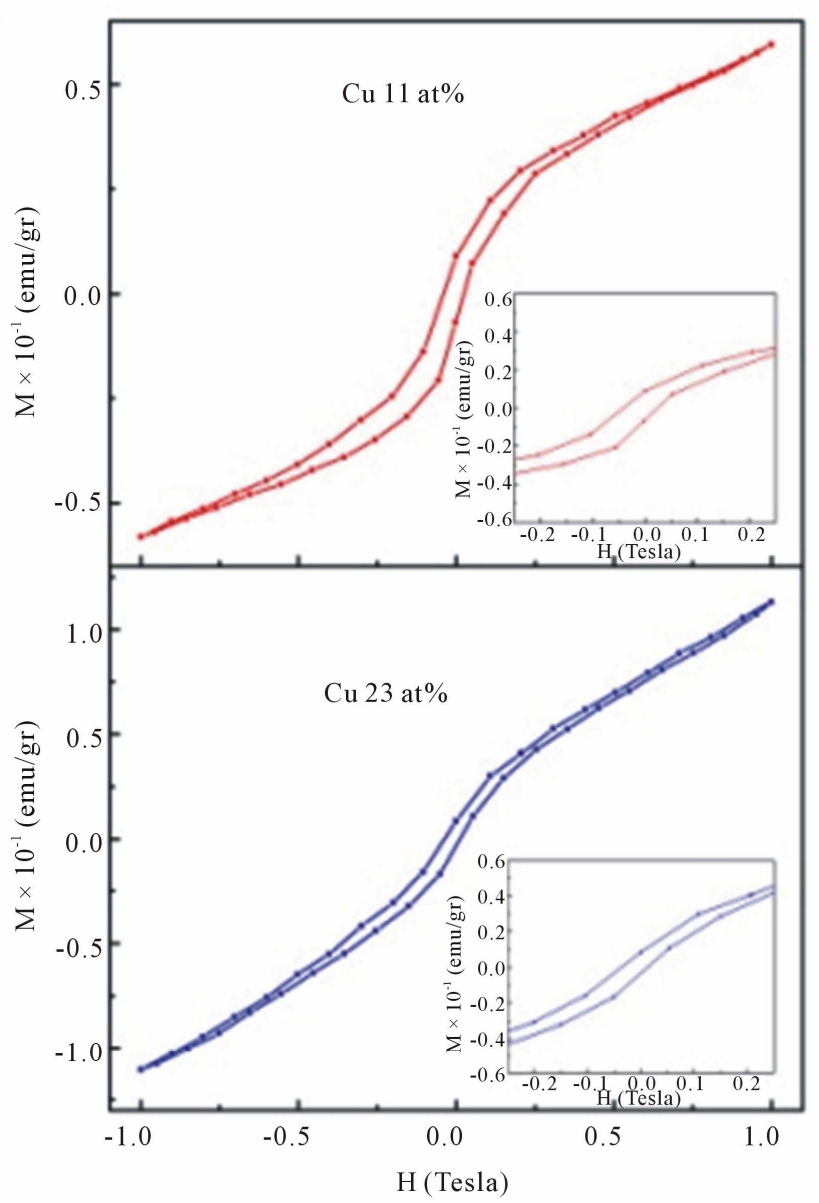

Figure 9. Room temperature $\mathrm{M}-\mathrm{H}$ curves for $\mathrm{Cu}$-doped nanocrystalline $\mathrm{ZnO}$ particles synthesized with various doping concentrations. 
Table 2. Magnetization value, remanence magnetization, and coercivity of Cu-doped nanocrystalline $\mathrm{ZnO}$ particles.

\begin{tabular}{ccccc}
\hline Sample & at $\%$ & $\mu_{\mathrm{B}} / \mathrm{Cu}^{2+}$ & $\mathrm{H}_{\mathrm{C}}(\mathrm{oe})$ & $\mathrm{M}_{\mathrm{R}} \times 10^{-2}(\mathrm{emu} / \mathrm{gr})$ \\
\hline \multirow{2}{*}{ Cu doped $\mathrm{ZnO}$} & 6 & 0.1008 & 270 & 1.39 \\
& 11 & 0.1512 & 329 & 0.77 \\
& 18 & 0.1862 & 415 & 1.14 \\
\hline
\end{tabular}

the origin of ferromagnetism in $\mathrm{Cu}$-doped $\mathrm{ZnO}$ was the formation of planar $\mathrm{CuO}$ nanophase, while Wei et al. [37] reported that there was no sign of ferromagnetism down to $10 \mathrm{~K}$ in pure $\mathrm{Cu}_{2} \mathrm{O}$ samples. Seehra et al. [38], on the other hand suggested that the $\mathrm{CuO}$ phase is paramagnet in the $\mathrm{Cu}_{x} \mathrm{Zn}_{1-x} \mathrm{O} / \mathrm{CuO}$ composite. Tong et al. [39], and Wang et al. [40] showed, that hydrogen incorporation in the sample can induced ferromagnetism. They believed, that hydrogen as shallow donor might be responsible for the enhancement of RTFM. Hydrogen induces RTFM, however, may not be valid in the present study because the detailed results of FTIR measurements clearly showed that hydrogen incorporation in our doped samples is almost independent with doping concentrations, indicating that hydrogen is not expected to play a crucial role in activating ferromagnetic behavior in our samples.

Chakraborti et al. [41] showed in their experiment that the effective moment per $\mathrm{Cu}$ atom is found to be very high for the lowest dopant concentrations of $\mathrm{Cu}$ and proposed that oxygen vacancies are the origin of ferromagnetism in $\mathrm{Cu}$-doped $\mathrm{ZnO}$ films, while theoretical study by Ye et al. [42] reported that oxygen vacancies tend to destroy the ferromagnetism in $\mathrm{Cu}$-doped $\mathrm{ZnO}$. However, a similar correlation between oxygen vacancy concentration and ferromagnetic behavior have been observed in several oxide-based dilute magnetic semiconductor materials such as Fe-doped $\mathrm{SnO}_{2}$ [43], Co doped $\mathrm{TiO}_{2}$ [44], $\mathrm{Co}$ doped $\mathrm{CeO}_{2}$ [45], Ni- and Mn-doped $\mathrm{ZnO}$ [46,47].

A defect mediated mechanism namely a bound magnetic polaron (BMP) [48] has been suggested as being responsible for the ferromagnetism in these systems. According to BMP model, bound electrons in defects like oxygen vacancies, can couple with $\mathrm{Cu}$ ions and cause ferromagnetic regions to overlap giving rise to long range ferromagnetic ordering in the samples.

From the energy band point of view, the BMP overlap to produce spin-split impurity band [49], and the electrons are able to transfer from the BMP impurity band to an unoccupied $3 \mathrm{~d}$ state of $\mathrm{Cu}$ ions at the Fermi level. Therefore, the ferromagnetism of the system will be established.

\section{Summary}

$\mathrm{Cu}$-doped nanocrystalline $\mathrm{ZnO}$ particles have been syn- thesized using the co-precipitation method and based on the structural, optical and magnetic measurements of our samples the following main point emerge:

1) Structure analysis indicates that $\mathrm{Cu}$ ions substitute for $\mathrm{Zn}$ ions without changing the wurtzite structure. The determined solubility limit of $\mathrm{Cu}$ in nanocrystalline $\mathrm{ZnO}$ particles by XRD studies is approximately 11 at $\%$.

2) The optical band gap was found to decrease with increasing doping concentrations, indicating a clear red shift.

3) All samples were found to exhibit ferromagnetic ordering at room temperature. The magnetization results showed that the ferromagnetism behavior is the intrinsic behavior.

4) The infrared absorption measurements showed clear evidence of hydrogen incorporation in our nanocrystalline $\mathrm{ZnO}$ particles. It is possible that hydrogen could induce ferromagnetism in our samples. Unfortunately, we do not have experimental evidence of the spin-spin interaction due to the incorporation of hydrogen atoms, and such analysis is beyond the scope of our work.

\section{REFERENCES}

[1] T. Dietl, H. Ohno and F. Matsukura, "Hole-Mediated Ferromagnetism in Tetrahedrally Coordinated Semiconductors," Physical Review B, Vol. 63, 2001, Article ID: 195205. doi:10.1103/PhysRevB.63.195205

[2] D. Chakraborti, G. R. Trichy, J. T. Prater and J. Narayan, "The Effect of Oxygen Annealing on $\mathrm{ZnO}: \mathrm{Cu}$ and $\mathrm{ZnO}$ : $(\mathrm{Cu}, \mathrm{Al})$ Diluted Magnetic Semiconductors," Journal of Physics D: Applied Physics, Vol. 40, No. 24, 2007, p. 7606. doi:10.1088/0022-3727/40/24/002

[3] S. Venkataraj, N. Ohash1, I. Sakaguchi, Y. Adachi, T. Ohgaki, H. Ryoken and H. Haneda, "Structural and Magnetic Properties of Mn-Ion Implanted ZnO Films," Journal of Applied Physics, Vol. 102, No. 1, 2007, Article ID: 014905. doi:10.1063/1.2752123

[4] S.-J. Han, J. W. Song, C.-H. Yang, S. H. Park, J.-H. Park, Y. H. Jeong and K. W. Rhie, "A Key to Room-Temperature Ferromagnetism in Fe-Doped $\mathrm{ZnO}: \mathrm{Cu}$," Applied Physics Letters, Vol. 81, No. 22, 2002, pp. 4212-4214. doi:10.1063/1.1525885

[5] K. Ueda, H. Tabata and T. Kawai, "Magnetic and Electric Properties of Transition-Metal-Doped ZnO Films," Applied Physics Letters, Vol. 79, No. 7, 2001, pp. 988-990. 
doi: $10.1063 / 1.1384478$

[6] T. Wakano, N. Fujimura, Y. Morinaga, N. Abe, A. Ashida and T. Ito, "Magnetic and Magneto-Transport Properties of ZnO:Ni Films," Physica E: Low-Dimensional Systems and Nanostructures, Vol. 10, No. 1-3, 2001, pp. 260-264. doi:10.1016/S1386-9477(01)00095-9

[7] S. J. Han, T. H. Jang, Y. B. Kim, B. G. Park, J. H. Park and Y. H. Jeong, "Magnetism in Mn-Doped ZnO Bulk Samples Prepared by Solid State Reaction," Applied Physics Letters, Vol. 83, No. 5, 2003, pp. 920-922. doi:10.1063/1.1597414

[8] D. C. Kundaliya, S. B. Ogale, S. E. Lofland, S. Dhar, C. J. Metting, S. R. Shinde, Z. Ma, B. Varughese, K. V. Ramanujachari, L. Salamanca-Riba and T. Venkatesan, "On the Origin of High-Temperature Ferromagnetism in the Low-Temperature-Processed Mn-Zn-O System," Nature Matter, Vol. 3, No. 10, 2004, pp. 709-714.

doi:10.1038/nmat1221

[9] H. L. Liu, J. H. Yang, Z. Hua, Y. J. Zhang, L. L. Yang, L. $\mathrm{Xiao}$ and Z. Xie, "The Structure and Magnetic Properties of Cu-Doped ZnO Prepared by Sol-Gel Method," Applied Surface Science, Vol. 256, No. 13, 2010, pp. 4162-4165.

[10] T. S. Herng, S. P. Lau, S. F. Yu, H. Y. Yang, X. H. Ji, J. S. Chen, N. Yasui and H. Inaba, "Origin of Room Temperature Ferromagnetism in $\mathrm{ZnO}: \mathrm{Cu}$ Films," Journal of Applied Physics, Vol. 99, No. 8, 2006, Article ID: 086101. doi:10.1063/1.2190711

[11] A. Tiwari, M. Snure, D. Kumar and J. T. Abiade, "Ferromagnetism in Cu-Doped $\mathrm{ZnO}$ Films: Role of Charge Carriers," Applied Physics Letters, Vol. 92, No. 6, 2008, Article ID: 062509. doi:10.1063/1.2857481

[12] D. B. Buchholz, R. P. H. Chang, J.-Y. Song and J. B. Ketterson, "Room-Temperature Ferromagnetism in $\mathrm{Cu}$ Doped ZnO Thin Films," Applied Physics Letters, Vol. 87, No. 8, 2005, Article ID: 082504. doi:10.1063/1.2032588

[13] L.-H. Ye, A. J. Freeman and B. Delley, "Half-Metallic Ferromagnetism in Cu-Doped ZnO: Density Functional Calculations," Physical Review B, Vol. 73, 2006, Article ID: 033203. doi:10.1103/PhysRevB.73.033203

[14] K. Sato and H. Katayama-Yoshida, "Microdischarge Optical Emission Spectroscopy as a Novel Diagnostic Tool for Metalorganic Chemical Vapor Deposition of (Ba, $\mathrm{Sr}) \mathrm{TiO}_{3}$ Films," JJAP: Japanese Journal of Applied Physics, Vol. 39, 2000, pp. 555-559. doi:10.1143/JJAP. 39.555

[15] D. L. Hou, X. J. Ye, H. J. Meng, H. J. Zhou, X. L. Li, C. M. Zhen and G. D. Tang, "Magnetic Properties of $n$-Type $\mathrm{Cu}$-Doped ZnO Thin Films," Applied Physics Letters, Vol. 90, No. 14, 2007, Article ID: 142502. doi:10.1063/1.2719034

[16] M. S. Park and B. I. Min, "Ferromagnetism in $\mathrm{ZnO}$ Codoped with Transition Metals: $\mathrm{Zn}_{1-x}(\mathrm{FeCo})_{x} \mathrm{O}$ and $\mathrm{Zn}_{1-x}(\mathrm{FeCu})_{x} \mathrm{O}$," Physical Review B, Vol. 68, 2003, Article ID: 224436.

[17] S. W. Jung, S-J. An, G.-C. Yi, C.-U. Jung, S.-I. Lee and S. Cho, "Ferromagnetic Properties of $\mathrm{Zn}_{1-x} \mathrm{Mn}_{x} \mathrm{O}$ Epitaxial Thin Films," Applied Physics Letters, Vol. 80, No. 4, 2002, pp. 4561-4563. doi:10.1063/1.1487927

[18] U. Ilyas, R. S. Rawat, T. L. Tan, P. Lee, R. Chen, H. D.
Sun, F. J. Li and S. Zhang, "Enhanced Indirect Ferromagnetic p-d Exchange Coupling of Mn in Oxygen Rich ZnO:Mn Nanoparticles Synthesized by Wet Chemical Method," Journal of Applied Physics, Vol. 111, No. 3, 2012, Article ID: 033503. doi:10.1063/1.3679129

[19] S. P. Prakoso and R. Saleh, "Hydrogen Incorporation in Undoped ZnO Nanoparticles," World Journal of Condensed Matter Physics, Vol. 1, No. 4, 2011, pp. 130-136. doi:10.4236/wjcmp.2011.14019

[20] G. K. Williamson and W. H. Hall, "X-Ray Line Broadening from Filled Aluminium and Wolfram," Acta Metallurgica, Vol. 1, No. 1, 1953, pp. 22-31. doi:10.1016/0001-6160(53)90006-6

[21] A. Janotti and C. G. Van de Walle, "Oxygen Vacancies in ZnO," Applied Physics Letters, Vol. 87, No. 12, 2005, Article ID: 122102. doi:10.1063/1.2053360

[22] R. Viswanatha, S. Chakraborty, S. Basu and D. D Sarma, "Blue-Emitting Copper-Doped Zinc Oxide Nanocrystals," The Journal of Physical Chemistry B, Vol. 110, No. 45, 2006, pp. 22310-22312.

[23] R. Viswanatha, S. Sapra, B. Satpati, P. V. Satyam, B. N. Dev and D. D. Sarma, "Understanding the Quantum Size Effects in ZnO Nanocrystals," Journal of Materials Chemistry, Vol. 14, 2004, pp. 661-668.

[24] P. Sharma, A. Gupta, K. V. Rao, F. J. Owens, R. Sharma, R. Ahuja, J. M. Osorio, B. Johansson and G. A. Gehring, "Ferromagnetism above Room Temperature in Bulk and Transparent Thin Films of Mn-Doped ZnO," Nature Matter, Vol. 2, 2003, pp. 673-677. doi:10.1038/nmat984

[25] A. Jagannatha Reddy, M. K. Kokila, H. Nagabhushana, R. P. S. Chakradhar, C. Shivakumara, J. L. Rao and B. M. Nagabhushana, "Structural, Optical and EPR Studies on $\mathrm{ZnO}: \mathrm{Cu}$ Nanopowders Prepared via Low Temperature Solution Combustion Synthesis," Journal of Alloys and Compounds, Vol. 509, No. 17, 2011, pp. 5349-5355. doi:10.1016/j.jallcom.2011.02.043

[26] Y. Chen and X. L. Xu, "Effect of Oxygen Deficiency on Optical Band Gap Shift in Er-Doped ZnO Thin Films," Physica B: Condensed Matter, Vol. 406, No. 17, 2011, pp. 3121-3124. doi:10.1016/j.physb.2011.03.078

[27] K. G. Kanade, B. B. Kale, J.-O. Baeg, S. M. Lee, C. W. Lee, S.-J. Moon and H. Chang, "Self-Assembled Aligned $\mathrm{Cu}$ Doped $\mathrm{ZnO}$ Nanoparticles for Photocatalytic Hydrogen Production under Visible Light Irradiation," Materials Chemistry and Physics, Vol. 102, No. 1, 2007, pp. 98-104. doi:10.1016/j.matchemphys.2006.11.012

[28] M. Y. Ghotbi, N. Bagheri and S. K. Sadrnezhaad, "Nanocrystalline Copper Doped Zinc Oxide Produced from Copper Doped Zinc Hydroxide Nitrate as a Layered Precursor," Advanced Powder Technology, Vol. 23, No. 3, 2012, pp. 279-283.

[29] H. Kleinwechter, C. Janzen, J. Knipping, H. Wiggers and P. Roth, "Formation and Properties of $\mathrm{ZnO}$ Nano-Particles from Gas Phase Synthesis Processes," Journal of Materials Science, Vol. 37, No. 20, 2002, pp. 4349-4360. doi:10.1023/A:1020656620050

[30] J. Das, I. R. Evans and D. Khushalani, "Zinc Glycolate: A Precursor to ZnO," Inorganic Chemistry, Vol. 48, No. 8, 2009, pp. 3508-3510. doi:10.1021/ic900067w 
[31] R. Saleh, L. Munisa and W. Beyer, "Infrared Absorption in a-SiC:H Alloy Prepared by d.c Sputtering," Thin Solid Films, Vol. 426, No. 1, 2003, pp. 117-123. doi:10.1016/S0040-6090(03)00003-8

[32] D. M. Joseph, R. Balagopal, R. F. Hicks, L. P. Sadwick and K. L. Wang, "Observation of Carbon Incorporation during Gallium Arsenide Growth by Molecular Beam Epitaxy," Applied Physics Letters, Vol. 53, No. 22, 1988, pp. 2203-2204. doi:10.1063/1.100281

[33] M. O. Manasreh, J. M. Baranowski, K. Pakula, H. X. Jiang and J. Lin, "Localized Vibrational Modes of Carbon-Hydrogen Complexes in GaN," Applied Physics Letters, Vol. 75, No. 5, 1999, pp. 659-661. doi: $10.1063 / 1.124473$

[34] P. Thakur, V. Bisogni, J. C. Cezar, N. B. Brookes, G. Ghiringhelli, S. Gautam, K. H. Chae, M. Subramanian, R. Jayavel and K. Asokan, "Electronic Structure of $\mathrm{Cu}-$ Doped ZnO Thin Films by X-Ray Absorption, Magnetic Circular Dichroism, and Resonant Inelastic X-Ray Scattering," Journal of Applied Physics, Vol. 107, 20110, Article ID: 103915.

[35] P. K. Sharma, R. K. Dutta and A. C. Pandey, "Doping Dependent Room-Temperature Ferromagnetism and Structural Properties of Dilute Magnetic Semiconductor ZnO: $\mathrm{Cu}^{2+}$ Nanorods," Journal of Magnetism and Magnetic Materials, Vol. 321, No. 24, 2009, pp. 4001-4005. doi:10.1016/j.jmmm.2009.07.066

[36] C. Sudakar, J. S. Thakur, G. Lawes, R. Naik and V. M. Naik, "Ferromagnetism Induced by Planar Nanoscale $\mathrm{CuO}$ Inclusions in $\mathrm{Cu}$-Doped $\mathrm{ZnO}$ Thin Films," Physical Review B, Vol. 75, 2007, Article ID: 054423. doi:10.1103/PhysRevB.75.054423

[37] M. Wei, N. Braddon, D. Zhi, P. A. Midgley, S. K. Chen, M. G. Blamire and J. L. MacManus-Driscoll, "Room Temperature Ferromagnetism in Bulk Mn-Doped $\mathrm{Cu}_{2} \mathrm{O}$," Applied Physics Letters, Vol. 86, No. 7, 2005, Article ID: 072514. doi:10.1063/1.1869547

[38] M. S. Seehra, P. Dutta, V. Singh, Y. Zhang and I. Wender, "Evidence for Room Temperature Ferromagnetism in $\mathrm{Cu}_{x} \mathrm{Zn}_{1-x} \mathrm{O}$ from Magnetic Studies in $\mathrm{Cu}_{x} \mathrm{Zn}_{1-x} \mathrm{O} / \mathrm{CuO}$ Composite," Journal of Applied Physics, Vol. 101, No. 9, 2007, Article ID: 09H107.

[39] L. N. Tong, T. Cheng, H. B Han, J. L. Hu, X. M. He, Y. Tong and C. M. Schneider, "Photoluminescence Studies on Structural Defects and Room Temperature Ferromagnetism in Ni and Ni-H Doped ZnO Nanoparticles," Journal of Applied Physics, Vol. 108, 2010, Article ID: 023906.
[40] Z. H. Wang, D. Y. Geng, S. Guo, W. J. Hu and Z. D. Zhang, "Ferromagnetism and Superparamagnetism of ZnCoO:H Nanocrystals,"Applied Physics Letters, Vol. 92, No. 24, 2008, Article ID: 242505. doi:10.1063/1.2948863

[41] D. Chakraborti, J. Narayan and J. T. Prater, "Room Temperature Ferromagnetism in $\mathrm{Zn}_{1-x} \mathrm{Cu}_{x} \mathrm{O}$ Thin Films," Applied Physics Letters, Vol. 90, No. 8, 2007, Article ID: 062504. doi:10.1063/1.2450652

[42] L.-H. Ye, A. J. Freeman and B. Delley, "Half-Metallic Ferromagnetism in $\mathrm{Cu}$-Doped $\mathrm{ZnO}$ : Density Functional Calculations," Physical Review B, Vol. 73, 2006, Article ID: 033203. doi:10.1103/PhysRevB.73.033203

[43] J. M. D. Coey, A. P. Douvalis, C. B. Fitzgerald and M. Venkatesan, "Ferromagnetism in Fe-Doped $\mathrm{SnO}_{2}$ Thin Films," Applied Physics Letters, Vol. 84, No. 8, 2004, pp. 1332-1334. doi:10.1063/1.1650041

[44] W. S. Yan, Z. H. Sun, Z. Y. Pan, Q. H. Liu, T. Yao, Z. Y. Wu, C. Song, F. Zeng, Y. Xie, T. D. Hu and S. Q. Wei, "Oxygen Vacancy Effect on Room-Temperature Ferromagnetism of Rutile Co: $\mathrm{TiO}_{2}$ Thin Films," Applied Physics Letters, Vol. 94, No. 4, 2009, Article ID: 042508. doi:10.1063/1.3075844

[45] Y.-Q. Song, H.-W. Zhang, Q.-Y. Wen, L. Peng and J. Q. Xiao, "Direct Evidence of Oxygen Vacancy Mediated Ferromagnetism of Co Doped $\mathrm{CeO}_{2}$ Thin Films on $\mathrm{Al}_{2} \mathrm{O}_{3}$ (0001) Substrates," Journal of Physics: Condensed Matter, Vol. 20, No. 25, 2008, Article ID: 255210. doi:10.1088/0953-8984/20/25/255210

[46] M. El-Hilo, A. A. Dakhel and A. Y. Ali-Mohamed, "Room Temperature Ferromagnetism in Nanocrystalline Ni-Doped ZnO Synthesized by Co-Precipitation," Journal of Magnetism and Magnetic Materials, Vol. 321, No. 14, 2009, pp. 2279-2283. doi:10.1016/j.jmmm.2009.01.040

[47] Z. H. Wang, D. Y. Geng and Z. D. Zhang, "RoomTemperature Ferromagnetism and Optical Properties of $\mathrm{Zn}_{1-x} \mathrm{Mn}_{x} \mathrm{O}$ Nanoparticles," Solid State Communication Vol. 149, No. 17-18, 2009, pp. 682-684. doi:10.1016/j.ssc.2009.02.016

[48] D. Chakraborti, G. Trichy, J. Narayan, J. T. Prater and D. Kumar, "Effect of Al Doping on the Magnetic and Electrical Properties of $\mathrm{Zn}(\mathrm{Cu}) \mathrm{O}$ Based Diluted Magnetic Semiconductors," Journal of Applied Physics, Vol. 102, No. 11, 2007, Article ID: 113908. doi:10.1063/1.2817824

[49] J. J. Lu, T. C. Lin, S. Y. Tsai, T. S. Mo and K. J. Gan, "Structural, Magnetic and Transport Properties of NiDoped ZnO Films," Journal of Magnetism and Magnetic Materials, Vol. 323, No. 6, 2011, pp. 829-832. doi:10.1016/j.jmmm.2010.11.025 